\title{
A longitudinal evaluation of dexamethasone and cortisol plasma concentrations in the dexamethasone suppression test before and during treatment with antidepressant drugs
}

Guthrie SK, Vartanian L, Grunhaus L, Hariharan M, Pande A, Haskett RF. A longitudinal evaluation of dexamethasone and cortisol plasma concentrations in the dexamethasone suppression test before and during treatment with antidepressant drugs.

Acta Psychiatr Scand 1990: 82: 427-432.

Thirty depressed in- and outpatients received serial dexamethasone suppression tests (DSTs). Plasma dexamethasone and cortisol concentrations were drawn at 1600 on the day following a 1-mg oral dose of dexamethasone. The first DST was performed after patients were drug-free for a period of 1 week; the second, third, and fourth DSTs while patients received antidepressant medication. Dexamethasone and cortisol concentrations drawn in the drug-free period correlated significantly. The cortisol to dexamethasone ratio changed significantly with time in DST nonsuppressors, suggesting that nonsuppression is associated with an altered pharmacodynamic response of the hypothalamopituitary-adrenal axis to dexamethasone during depression. When dexamethasone concentrations from the drug-free period were compared with those drawn during antidepressant treatment, no significant differences were noted.

\author{
S. K. Guthrie ${ }^{1.3}$, L. Vartanian ${ }^{2}$, \\ L. Grunhaus ${ }^{3}$, M. Hariharan ${ }^{3}$, A. Pande ${ }^{3}$, \\ R. F. Haskett ${ }^{3}$ \\ ${ }^{1}$ College of Pharmacy, University of Michigan, \\ ${ }^{2}$ Beaumont Hospital, ${ }^{3}$ Department of Psychia- \\ try, University of Michigan Medical Center, \\ Ann Arbor, Michigan, USA
}

Key words: dexamethasone; dexamethasone suppression test; cortisol; antidepressant drug Sally K. Guthrie, Pharm. D., Assistant Professor of Pharmacy, College of Pharmacy, University of Michigan, Ann Arbor, Ml 48109-1065, USA

Accepted for publication July 21, 1990
Pharmacokinetic factors may be important in interpreting the dexamethasone suppression test (DST). Several studies have found an inverse relationship between the plasma dexamethasone and cortisol concentrations following dexamethasone. In most studies a DST nonsuppressor is designated by a cortisol plasma concentration of $>5 \pm 1 \mu \mathrm{g} \%$ at approximately 1600 on the day following dexamethasone administration. It is likely that the plasma concentration of dexamethasone resulting from a $1-\mathrm{mg}$ oral dose might influence DST results to some degree. Arana et al. (1) noted that DST dexamethasone plasma concentrations were lower in the nonsuppressors compared with the suppressors in his population. Wiedemann \& Holsboer (2) analyzed dexamethasone pharmacokinetics following a 1-mg oral dexamethasone dose and found that the dexamethasone plasma concentrations were lower in nonsuppressors. Several other groups have also found a significant negative correlation between the dexamethasone and cortisol plasma concentrations following dexamethasone, although this factor alone has not accounted for DST nonsuppression in depressed persons (3-5).

An intteraction between dexamethasone and commonly used medicine could result in erroneous DST results. Reports describing drug interactions between dexamethasone and phenobarbital, phenytoin, estrogens or magnesium trisilicate have appeared in the literature (6-9). Two groups of investigators have reported that antidepressants do not affect DST results $(10,11)$. Although Hunt et al. (10) found that concomitant psychotropic medication did not effect dexamethasone concentrations, they did not restudy the same patients at a later time point. Poland et al. (11) studied the same patients at 3 time points and reported that there were no significant differences in dexamethasone concentrations before, during, or after antidepressant treatment.

Carson et al. (12) examined the ratio of DST cortisol to dexamethasone plasma concentration. This ratio adjusts the cortisol concentration using the dexamethasone concentration. They found that the cortisol to dexamethasone ratios were significantly higher in DST nonsuppressors than in both normal controls and depressed patients who were suppressors. A longitudinal study of this relationship would reveal whether the relationship between dexamethasone and cortisol changes as the DST cortisol concentrations normalizes during antidepressant treatment.

To more fully explore some of these issues, in - and outpatients underwent serial DSTs, both when drugfree for at least one week and during treatment with 


\section{Guthrie et al.}

commonly used antidepressant drugs. We have addressed several questions in our group of patients: Is the dexamethasone concentration negatively correlated with the cortisol concentration following a dexamethasone dose in our population? Is there a significant change in dexamethasone concentrations when values obtained during antidepressant treatment are compared with values obtained in the same patients before they received antidepressants? Do DST dexamethasone concentrations show significant variation if they are measured at different time points during a course of antidepressant medication? Does the cortisol to dexamethasone ratio change longitudinally as DST nonsuppressors convert to suppressors?

\section{Materials and methods}

We retrospectively evaluated 30 inpatients $(n=15)$ and outpatients $(n=15)$ from the depression program of the Department of Psychiatry at the University of Michigan Medical Center. Serial DSTs were performed in these patients between September 1984 and March 1987. All patients underwent one DST after being drug-free for at least 1 week, and three subsequent DSTs while receiving the same antidepressant medication. The dosage of antidepressant remained unchanged for at least $7 \mathrm{~d}$ prior to each DST completed during treatment.

Patients receiving medication other than antidepressants were included in the analyses if these drugs had never been reported to alter hepatic drug metabolism. Drug-free DSTs were performed on inpatients during the index admission and most of the subsequent DSTs were performed on an outpatient basis. All DSTs in the outpatients were performed on an outpatient basis. Patients were receiving antidepressant medication when the second, third and fourth DSTs were performed. The time period between the drug-free DST and the second DST was $6.3 \pm 3.8$ weeks; the third DST followed the second by $2.0 \pm 1.7$ weeks, and the fourth DST followed the third by $2.5 \pm 2.0$ weeks.

All patients met the Research Diagnostic Criteria for major depressive disorder. The mean Hamilton Rating Scale for Depression score during the pretreatment period was $18.6 \pm 9.1$, the mean age of the patients was $42.2 \pm 15.1$ years (mean $\pm \mathrm{SD}$ ), and the male-female ratio was $12 / 18$. The medicines included in the analysis were desipramine $(n=10)$, imipramine $(n=10)$, phenelzine $(n=3)$, tranylcypromine $(n=3)$, lithium $(n=7)$ and nortriptyline $(n=4)$. Some patients received combinations of these agents. Eight patients received nonpsychiatric medicines or benzodiazepines but none received neuroleptics.

The DST followed the procedure described by
Carroll et al. (13) using $1 \mathrm{mg}$ of dexamethasone. Both dexamethasone and cortisol plasma concentrations were drawn at 1600 on the following day and the result was considered nonsuppressive or abnor$\mathrm{mal}$ if the 1600 post-dexamethasone plasma cortisol value exceeded $5 \mu \mathrm{g} \%$. All samples were assayed by the same laboratory. Plasma cortisol was measured by the competitive protein binding technique of Pegg \& Keane (14) as modified by De la Pena \& Goldzieher (15). Plasma dexamethasone concentrations were measured by radioimmunoassay (16) using ${ }^{3} \mathrm{H}$-dexamethasone as a tracer, and dextrancoated charcoal to separate bound and free ligands. The antibody was obtained from rabbit antiserum raised against a bovine serum albumin conjugate of dexamethasone-3-carboxymethyloxime-hemisuccinate, and was very specific for dexamethasone. Endogenous steroids cross-reacted $<1 \%$ and cortisol cross-reaction was not detectable until concentrations were $>16 \mu \mathrm{g} / \mathrm{dl}(0.5 \%$ cross-reactivity $)$. Assay sensitivity was $10 \mathrm{pg} /$ tube or $100 \mathrm{pg} / \mathrm{ml}$ using $100 \mu \mathrm{l}$ of sample, and linear in the range from 0 to $1500 \mathrm{ng} / \mathrm{dl}$. The interassay coefficients of variation were $6.5 \%$ and $5.0 \%$ and the intra-assay coefficients of variation were $5.5 \%$ and $4.8 \%$ at mean dexamethasone values of $109 \mathrm{ng} / \mathrm{dl}$ and $380 \mathrm{ng} / \mathrm{dl}$, respectively. Assay recovery was $93 \pm 5 \%$ in the range 0 to $1500 \mathrm{ng} / \mathrm{dl}$.

Neither dexamethasone nor cortisol plasma concentrations conformed to a normal distribution; consequently, log-transformed values were used in the statistical analyses. The pre-treatment DST dexamethasone and cortisol plasma concentrations were examined using correlational analysis. The cortisol and dexamethasone plasma concentrations obtained during the serial DSTs were analyzed using one- or two-way ANOVA for repeated measures and unpaired Student's $t$-test with Bonferroni adjustment of multiple tests. These statistics were performed using the StatView statistical software package (17).

\section{Results}

The dexamethasone and cortisol plasma concentrations at the drug-free time point are displayed in Fig. 1. At this time post-DST cortisol and dexamethasone plasma concentrations were correlated $(r=-0.49, P<.01, n=30)$. However, no significant correlation was found between age and postDST cortisol or dexamethasone plasma concentrations.

In the total group of patients the mean 1600 DST dexamethasone concentrations were lowest during the drug-free period but there was no statistically significant time effect when the plasma dexamethasone concentrations were analyzed using the one- 


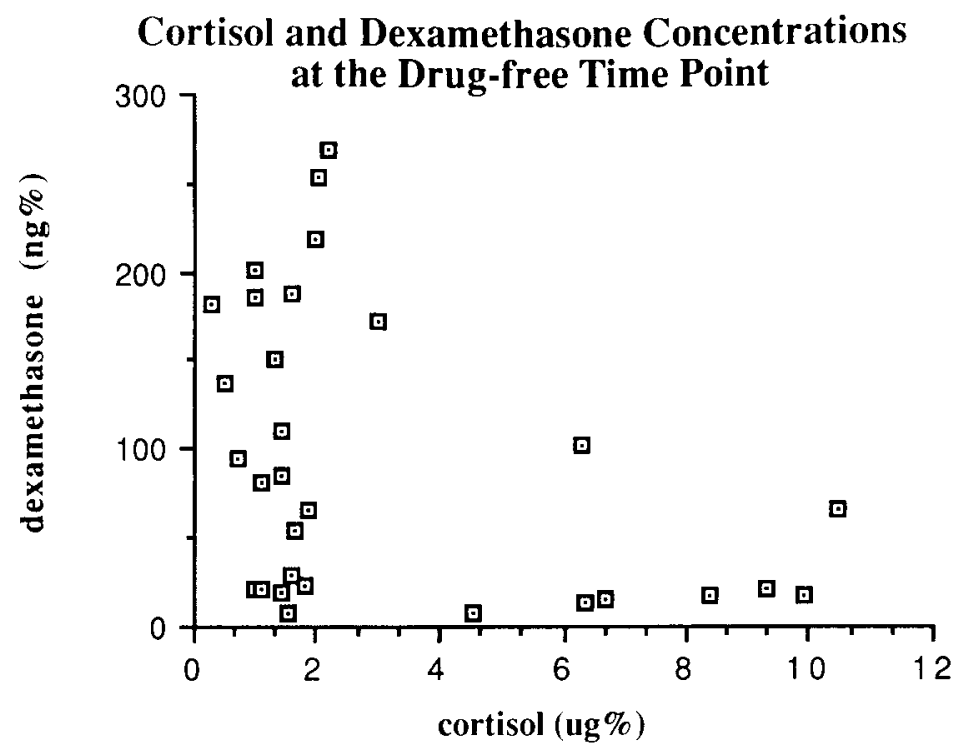

Fig. 1. Cortisol $(\mu \mathrm{g} \%)$ and dexamethasone plasma concentrations $(\mathrm{ng} / 100 \mathrm{ml})$ at 1600 in all 30 patients during the drug-free period.

way ANOVA for repeated measures (Table 1).

Dexamethasone concentrations in the patients who received imipramine $(n=10)$, desipramine $(n=10)$, or the other antidepressants $(n=10)$ were also compared using two-way ANOVA for repeated measures. This analysis revealed no group, or time effects and no group $\times$ time interaction (Table 1).

During the drug-free period 7 of the 30 patients $(23 \%)$ were nonsuppressors. DST dexamethasone concentrations obtained at 1600 in suppressors and nonsuppressors were compared at all time points using a two-way ANOVA for repeated measures. There was no significant group $\times$ time interaction, nor were there any significant time or overall group effects (Fig. 2). Although the overall group effect did not reach statistical significance there was a trend
Table 1. Plasma dexamethasone concentrations (ng/ $100 \mathrm{ml}$ ) in patients before and during treatment with desipramine, imipramine, or other antidepressants (mean \pm SD)

\begin{tabular}{|c|c|c|c|c|}
\hline $\begin{array}{l}\text { DST } \\
\text { Time point }\end{array}$ & $\begin{array}{c}\text { Total } \\
\text { population }\end{array}$ & Imipramine & Desipramine & Other \\
\hline \multicolumn{5}{|l|}{ Drug-free } \\
\hline First & $94.6 \pm 81.4$ & $105.5 \pm 93.9$ & $67.1 \pm 62.5$ & $111.3 \pm 85.7$ \\
\hline \multicolumn{5}{|c|}{ During antidepressant } \\
\hline Second & $123.0 \pm 97.0$ & $96.5 \pm 74.1$ & $129.6 \pm 122.5$ & $142.9 \pm 92.6$ \\
\hline Third & $128.1 \pm 90.3$ & $127.1 \pm 91.6$ & $125.2 \pm 84.8$ & $131.9 \pm 103.3$ \\
\hline \multirow[t]{2}{*}{ Fourth } & $120.6 \pm 91.8$ & $110.8 \pm 97.9$ & $131.7 \pm 107.4$ & $119.1 \pm 76.2$ \\
\hline & $\begin{array}{l}\text { NS for time } \\
\text { effect, one-way } \\
\text { ANOVA for } \\
\text { repeated } \\
\text { measures }\end{array}$ & \multicolumn{3}{|c|}{$\begin{array}{l}\text { NS for time and group effects, two-way ANOVA for } \\
\text { repeated measures }\end{array}$} \\
\hline
\end{tabular}

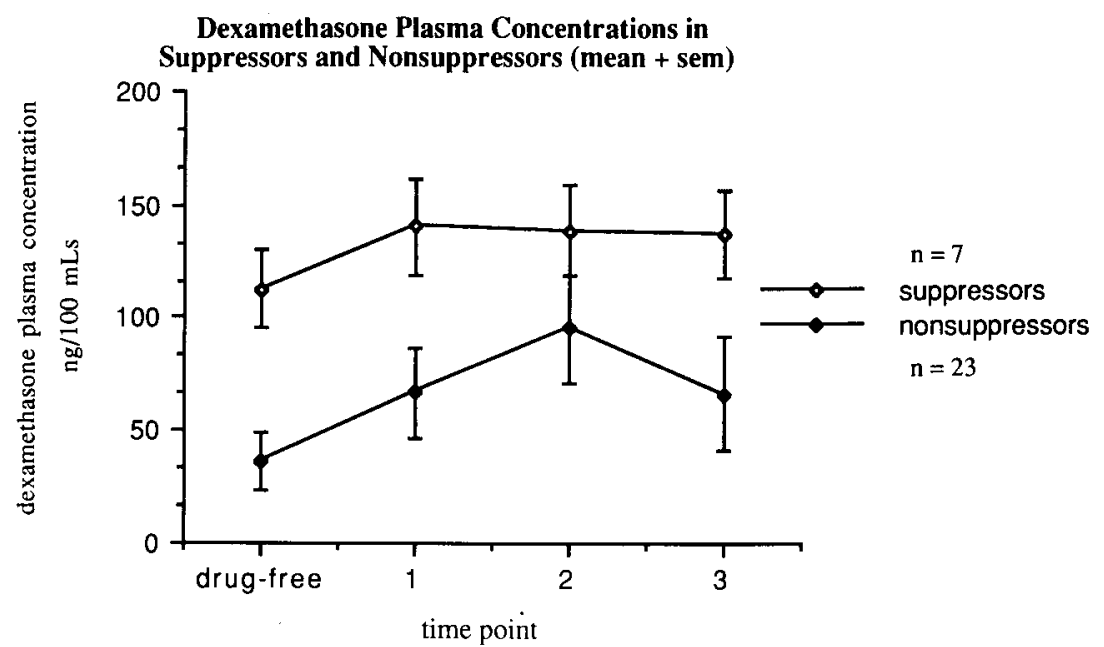

Fig. 2. Dexamethasone plasma concentrations $(\mathrm{ng} / 100 \mathrm{ml})$ at 1600 in patients who were suppressors $(n=23)$ or nonsuppressors $(n=7)$ during the drug-free period, and subsequent time points. 
towards lower dexamethasone concentrations in the nonsuppressors $(F=3.82, P=0.06)$. Individual unpaired $t$-tests performed at the separate time points revealed significantly lower dexamethasone concentrations in the nonsuppressors during the drug-free period $(P=0.01)$ and at the first time point during antidepressant treatment $(P<0.05)$, although this last difference was not significant when subjected to the Bonferroni adjustment.

The 1600 DST cortisol concentrations were analyzed using a two-way ANOVA for repeated measures. Since the group $\times$ time interaction was significant $(F=12.68, P<0.001)$ the overall tests for group and time effects are invalid. Individual unpaired $t$-tests for groups were performed at each time point, and a significant difference, using the Bonferroni adjustment, was noted between the groups at the first time point $(P<0.001)$. These significant statistical findings are explained by the following; nonsuppressors exhibited higher cortisol concentrations than suppressors during the pretreatment time point, and most of the nonsuppressors became suppressors during antidepressant treatment.

The ratio of cortisol to dexamethasone was compared between the suppressors at all time points $(n=20)$ and the nonsuppressors who suppressed during all 3 DSTs performed during antidepressant treatment $(n=4)$, using a two-way ANOVA for repeated measures (Fig. 3). The group $\times$ time interaction ( $n=24, F=7.73, P<0.001)$ was significant, thus invalidating the overall test for group and time effects. This interaction shows that a significant decrease in the cortisol to dexamethasone ratio occurred in the nonsuppressors as they converted to suppressors. Individual $t$-tests performed for each time point revealed a significant difference, when subjected to the Bonferroni adjustment, between the groups at the first time point $P<0.001$ ).

\section{Discussion}

Arana et al. (1) and Carson et al. (12) found negative correlations between 1600 DST dexamethasone and cortisol plasma concentrations. Carr et al. (4) found a significant inverse curvilinear relationship between DST dexamethasone and cortisol plasma concentrations. Since the dexamethasone concentration alone explained only a small amount of the variance of the cortisol concentrations, these authors concluded that an abnormal DST result is also a function of hypothalamopituitary-adrenal (HPA) axis dysregulation in MDD patients who are nonsuppressors. We also found that pre-treatment $1600 \mathrm{DST}$ dexamethasone correlated negatively with cortisol plasma concentrations, explaining about $15 \%$ of the variance of cortisol concentrations.

Poland et al. (11) studied 10 endogenous depressives and found no significant differences in the 0700,1500 or 2300 post-DST dexamethasone plasma concentrations when he compared values obtained prior to, during, and after, treatment with antidepressants (primarily imipramine). However, this group examined only one time point during antidepressant treatment and could not determine whether dexamethasone concentrations might be altered by the duration of antidepressant therapy. We have performed 3 serial DSTs during antidepressant therapy and have found no evidence that the duration of antidepressant therapy alters post-DST dexamethasone plasma concentrations.

Our finding that antidepressant drugs in general, and desipramine and imipramine specifically, do not significantly alter the 1600 DST dexamethasone

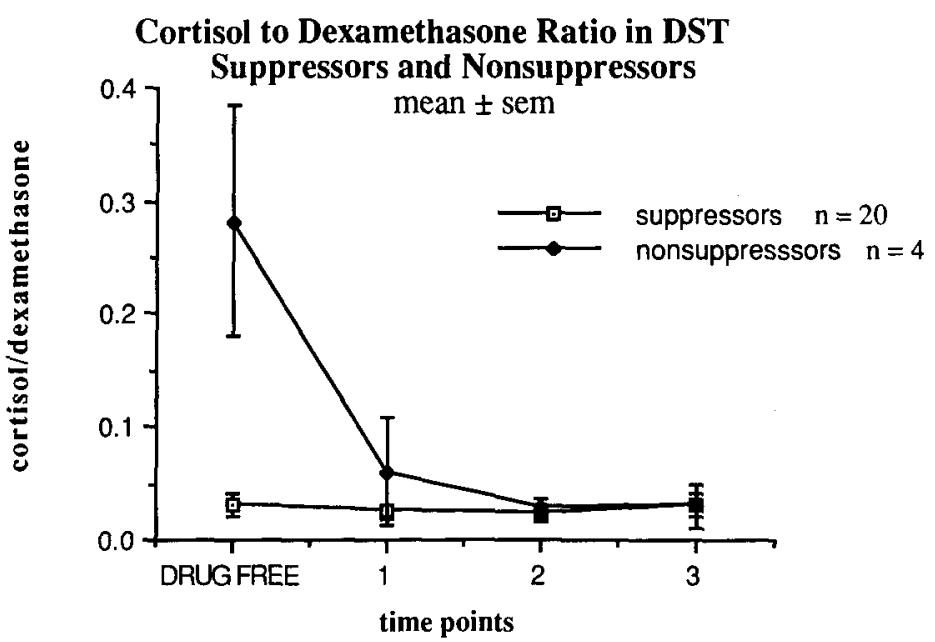

Fig. 3. Cortisol to dexamethasone ratios at 1600 in patients who were consistently suppressors at all time points $(n=20)$ or nonsuppressors during the drug-free period but suppressors at the 3 subsequent time points during antidepressant therapy $(n=4)$. 
concentrations during serial DSTs confirms and expands the results previously reported by Poland et al. (11).

Although it was not statistically significant when analyzed using the ANOVA with repeated measures, the nonsuppressors in our group exhibited lower 1600 dexamethasone concentrations than the suppressors, both during the drug-free period and when they received antidepressants. The lack of a statistically significant difference may be due to the small sample population, since $t$-tests showed significant differences at 2 of the time points and a significant group effect was found when one patient with a marginally high cortisol $(4.53 \mu \mathrm{g} \%)$ was included in the nonsuppressor group. Wiedemann \& Holsboer (2) found that nonsuppressors exhibited significantly lower dexamethasone plasma concentrations at most time points compared with suppressors following a single oral dose of dexamethasone. However, they did not study their patients longitudinally to determine whether dexamethasone concentrations changed when nonsuppressors converted to suppressors during treatment. Poland et al. (11) found no change in dexamethasone concentrations in either suppressors or nonsuppressors when he compared 1600 DST samples drawn prior to treatment, during treatment, and post-treatment in his depressed population. In our nonsuppressors the dexamethasone concentrations did not change significantly over time, regardless of their suppressor status.

In the manner previously described by Carson et al. (12) we adjusted the cortisol concentration with the concentration of dexamethasone. As the cortisol concentrations normalized over time in our nonsuppressors, the cortisol to dexamethasone ratios in the nonsuppressors showed a significant decrease. The cortisol to dexamethasone ratios in nonsuppressors decreased to values similar to those observed in the DST suppressors and were not accompanied by a significant change in dexamethasone concentration.

\section{Conclusion}

In conclusion, we found the same inverse correlation between dexamethasone and cortisol concentrations that has been reported by other investigators. In agreement with these investigators, we do not believe that this relationship totally explains the phenomenon of DST nonsuppression in depression. We also found that antidepressant drug therapy in general, and specifically in patients receiving imipramine or desipramine, did not statistically significantly change in the 1600 DST plasma dexamethasone concentrations in our patient population. Further research would determine whether the de- pressed state is another important variable that affects dexamethasone plasma concentrations; unfortunately we were not able to evaluate this in our data set.

The difference between the dexamethasone plasma concentrations in DST suppressors and nonsuppressors was not statistically significant (perhaps because of the small number of nonsuppressors in our sample), but we found a definite trend towards lower dexamethasone plasma concentrations in nonsuppressors. Although the dexamethasone concentrations did not change significantly over time in either the suppressors or nonsuppressors, we found that the cortisol to dexamethasone ratio in DST nonsuppressors decreased significantly over time as nonsuppressors converted to suppressors. This finding strengthens the hypothesis that nonsuppression is associated with an altered pharmacodynamic response of the HPA to dexamethasone during depression.

\section{References}

1. Arana GW, Workman RJ, Baldessarini RJ. Association between low plasma levels of dexamethasone and elevated levels of cortisol in psychiatric patients given dexamethasone. Am J Psychiatry 1984: 141: 1619-1620.

2. WiedemanN K, Holsboer F. Plasma dexamethasone kinetics during the DST after oral and intravenous administration of the test drug. Biol Psychiatry 1987: 22: 1340-1348.

3. Johnson GF, HunT G, KERR K, CaTerson I. Dexamethasone suppression test (DST) and plasma dexamethasone levels in depressed patients. Psychiatry Res 1984: 13: 305-313.

4. Carr V, Morris H, Gilliland J. The effect of serum dexamethasone concentrations in the dexamethasone suppression test. Biol Psychiatry 1986: 21: 735-743.

5. Berger M, Pirke K-M, Doerr P, Krieg J-C, von ZERSSEN D. The limited utility of the dexamethasone suppression test for the diagnostic process in psychiatry. $\mathrm{Br} \mathrm{J}$ Psychiatry 1984: 145: 372-382.

6. Brooks SM, Werk EE, ACKerman SJ, Sullivan I, THRASHER K. Adverse effects of phenobarbital on corticosteroid metabolism in patients with bronchial asthma. $\mathrm{N}$ Engl J Med 1972: 286: 1125-1128.

7. Haque N, Thrasher K, Werk EE, Knowles HC, SHOLITON LJ. Studies on dexamethasone metabolism in man: effect of diphenylhydantoin. Clin Endocrinol Metab 1972: 34: 44-50.

8. Dommisse C, Hayes PE, Kwentus JA. Effect of estrogens on the dexamethasone suppression test in nondepressed women. J Clin Psychopharmacol 1985: 5: 315-319.

9. NAGgar VF, Khalil SA, Gouda MW. Effect of concomitant administration of magnesium trisilicate on GI absorption of dexamethasone in humans. J Pharm Sci 1978: 67: 1029-1030.

10. Hunt GE, Johnson GFS, CATERSON ID. The effect of age on cortisol and plasma dexamethasone concentrations in depressed patients and controls. J Affective Disord 1989: 17: 21-32.

11. Poland RE, Rubin RT, Lesser IM. Serum dexamethasone concentrations in endogenous depressives before, during and after treatment: preliminary observations. Biol Psychiatry 1988: $23: 705-710$. 


\section{Guthrie et al.}

12. Carson SW, Halbreich U, Yeh CM, asnis G, GOLDSTEIN S. Cortisol suppression per nanogram per milliliter of plasma dexamethasone in depressive and normal subjects. Biol Psychiatry 1988: 24: 569-577.

13. Carroll BJ, Feinberg M, Greden JF et al. A specific laboratory test for the diagnosis of melancholia: standardization, validation and clinical utility. Arch Gen Psychiatry 1981: 38: 15-22.

14. Pegg PJ, Keane PM. The simultaneous estimation of plasma cortisol and transcortin binding characteristics by a competitive protein binding technique. Steroids 1969: 14: $705-715$.
15. De la Pena A, Goldziener JW. Practical determination of total plasma cortisol by use of competitive protein binding. In: Selected methods of clinical chemistry, vol. 8. Washington, DC: American Clinical Chemistry Association, 1977: 105 .

16. Hitchens $M$, Hogans AF. Radioimmunoassay for dexamethasone in plasma. Clin Chem 1974: 20: 266-269.

17. Statview, the graphic statistics utility for the Macintosh. Calabasas, CA: Brain Power, 1985. 